\title{
THE EFFECT OF NANOCHITOSAN FROM RHINOCEROS BEETLE (Xylotrupes gideon) TOWARDS GIC SURFACE ROUGHNESS ON CRITICAL PH OF THE SALIVA
}

Deviyanti Pratiwi ${ }^{\star}$, Gabriel Rainheart Genesis ${ }^{\star *}, K_{0}$ mariah ${ }^{\star * *}$, Rosalina Tjandrawinata ${ }^{\star \star \star *}$

${ }^{*}$ Departement of Dental Material, Faculty of Dentistry, Trisakti University, Indonesia

**Undergraduate Student, Faculty of Dentistry, Trisakti University, Indonesia

${ }^{* * *}$ Departement of Biology Oral, Faculty of Dentistry, Trisakti University, Indonesia

${ }^{\star * * \star D e p a r t e m e n t}$ of Dental Material, Faculty of Dentistry, Trisakti University, Indonesia

Correspondence : dvyanti88@gmail.com

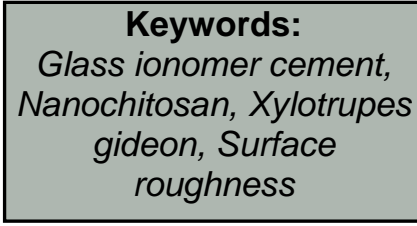

\section{ABSTRACT}

Background: Xylotrupes gideon is a harmful insect because it damages the shoots of coconut trees. Xylotrupes gideon has begun to be used in the form of nanochitosan as an alternative in dentistry. The addition of nanochitosan to Glass lonomer Cement (GIC) material is a modification to improve the properties of GIC, such as surface roughness caused by acidic conditions (critical saliva pH). Nano-sized chitosan is able to increase stability and better absorption, thus inhibit demineralization and increase tooth hardness. This research aimed to investigate the effect of nanochitosan from Xylotrupes gideon on the surface roughness of GIC at critical saliva $\mathrm{pH}$.

Method: This research type conducted is an experimental laboratory. Samples of $10 \mathrm{~mm}$ (height) $\times 2 \mathrm{~mm}$ (diameter) divided into 2 groups, (A) Unmodified GIC (control group), (B) GIC modified with $10 \%$ nanochitosan solution. Samples of the treatment and control group are stored in the incubator at $37^{\circ} \mathrm{C}$ for 1 hour before early surface roughness testing and continued in critical saliva $\mathrm{pH}(5,5)$ for 7 days in the incubator before the final test. The surface roughness tester using sutrotonic $s-100$ series.

Result: There was an increase in the surface roughness of conventional GIC by $0.133 \mu \mathrm{m}$ and GIC nanochitosan by $0.122 \mu \mathrm{m}$. The results of the paired ttest before and after immersion in the two groups showed that there was a significant difference $(p<0.05)$ between conventional GIC and nanochitosan GIC. The independent $t$-test results showed that there was no significant difference ( $p>0.05)$ between the nanochitosan GIC and conventional GIC.

Conclusion: Nanochitosan can reduce the surface roughness value of GIC at critical saliva $\mathrm{pH}$, although there is no significant difference to conventional GIC.

\section{PENDAHULUAN}

Semen lonomer Kaca (SIK) masih menjadi pilihan untuk bahan restoratif karena sifat dan karakteristiknya. SIK terbentuk dari reaksi asam polimer lemah dengan cairan yaitu bubuk kaca kalsium fluoroaminosilikat dan larutan asam poliakrilat yang memiliki sifat berikatan baik dengan struktur gigi, biokompatibel dengan keadaan pulpa, dan melepaskan fluor. ${ }^{1}$ SIK memiliki beberapa kelemahan sebagai bahan restorasi seperti rentan terhadap kelembaban pada saat setting, waktu kerja yang lama, mudah larut dalam air yang berdampak terhadap kekerasan dan daya tahan dari permukaan restorasi. ${ }^{2}$ Sifat larutnya suatu bahan yang kurang baik dapat mempengaruhi kekasaran permukaan dari SIK. ${ }^{3}$

Kekasaran permukaan menentukan kualitas dari bahan restorasi. Kekasaran permukaan pada bahan restorasi dapat menyebabkan perubahan warna pada tumpatan dan akumulasi plak gigi yang 
jika tidak ditangani dalam jangka panjang dapat mengakibatkan kerusakan gigi serta jaringan pendukungnya. ${ }^{4}$ Permukaan yang kasar menyebabkan retensi dan proliferasi dari berbagai mikroorganisme yang menimbulkan masalah pada rongga mulut dan penyakit periodontal. ${ }^{1}$ SIK merupakan bahan restorasi yang digunakan dalam jangka waktu lama dalam rongga mulut dan dapat mengalami perubahan pada kekasaran permukaan karena kontaminasi dari saliva maupun asam, sehingga perlu dilakukan evaluasi terhadap nilai kekasaran permukaan. Parameter pengukuran yang digunakan adalah kekasaran rata-rata garis tengah (Ra). Menurut Bollen (2017), nilai kekasaran permukaan kritis untuk kolonisasi bakteri dari bahan restorasi berada di angka 0,2 $\mu \mathrm{m}$. Jika nilai kekasaran permukaan di atas angka 0,2 $\mu \mathrm{m}$ maka berpotensi meningkatkan perlekatan bakteri dan plak gigi yang dapat meningkatkan risiko karies. ${ }^{5}$

Saliva merupakan salah satu asam yang terdapat dalam rongga mulut. Semakin rendah nilai $\mathrm{pH}$ saliva maka kandungan asam dalam larutan saliva lebih banyak, sebaliknya jika nilai pH saliva tinggi maka kandungan basa dalam larutan saliva yang lebih banyak. ${ }^{6}$ Perubahan dari $\mathrm{pH}$ saliva dapat dipengaruhi beberapa faktor seperti diet, stimulasi sekresi saliva, dan aktivitas oral mikroorganisme. Perubahan dari $\mathrm{pH}$ saliva secara berulang dapat mempengaruhi struktur gigi dan bahan restorasi. ${ }^{7}$

Kitosan adalah biomaterial dalam kedokteran gigi yang didapatkan dari cangkang kepiting, udang dan serangga melalui proses deasetilasi alkalin kitin. Salah satu serangga yang dapat dimanfaatkan menjadi kitosan adalah kumbang tanduk (Xylotrupes gideon). Serangga jenis ini dianggap merugikan karena merusak pucuk tanaman kelapa, untuk memanfaatkan kerugian ini maka diolah menjadi kitosan. ${ }^{8}$ Kitosan merupakan basa lemah dan tidak mudah larut dalam air dan pelarut organik, namun dapat larut dalam cairan yang asam seperti asam asetat. Penambahan kitosan sebesar $10 \% \mathrm{v} / \mathrm{v}$ pada larutan SIK ditemukan dapat menurunkan kekasaran permukaan jika dibandingkan SIK konvensional pada perendaman minuman isotonik. ${ }^{9}$ Pengembangan kitosan menadi bentuk nano juga dapat meningkatkan fungsi dari kitosan yaitu menghambat demineralisasi email. ${ }^{10}$

Tujuan dari penelitian ini adalah untuk mengetahui pengaruh nanokitosan kumbang tanduk (Xylotrupes Gideon) terhadap kekasaran permukaan SIK pada pH saliva kritis $(5,5)$ dengan perendaman pada suhu $37^{\circ} \mathrm{C}$ selama 7 hari.

\section{METODE PENELITIAN}

Desain penelitian ini adalah eksperimental laboratorik dengan rancangan pretest dan posttest control design untuk melihat pengaruh nanokitosan kumbang tanduk (Xylotrupes gideon) terhadap kekasaran permukaan SIK pada $\mathrm{pH}$ saliva kritis $(5,5)$. Penelitian ini menggunakan semen ionomer kaca GC Fuji Tipe IX (GC corporation, Tokyo, Japan). Larutan nanokitosan dicampur dengan liquid SIK (GC IX High Strength Posterior Restoration) dalam rasio $10 \% \mathrm{v} / \mathrm{v}$. Jumlah sampel yang digunakan dalam penelitian ini berjumlah 12 sampel dengan diameter $10 \mathrm{~mm} \times 2 \mathrm{~mm}$ yang terbagi atas 2 kelompok. Kelompok 1 merupakan kelompok SIK konvensional (kelompok kontrol) yang terdiri atas 6 sampel, kelompok 2 merupakan kelompok SIK modifikasi nanokitosan kumbang tanduk (Xylotrupes gideon) yang terdiri atas 6 sampel.

Penelitian diawali dengan mengencerkan larutan nanokitosan kumbang tanduk dengan konsentrasi 3000 ppm menjadi konsentrasi 200 ppm dengan menggunakan air tanpa mineral. Larutan nanokitosan dengan konsentrasi 200 ppm diambil sebanyak 0,3 $\mathrm{mL}$ dan ditambahkan ke dalam 2,7 mL liquid SIK untuk mendapatkan larutan 
nanokitosan dengan konsentrasi $10 \% \quad \mathrm{v} / \mathrm{v}$. Kemudian larutan nanokitosan dan liquid SIK dicampur hingga homogen sebelum digunakan.

Pembuatan sampel dilanjutkan dengan mengoleskan vaseline pada mould dengan ukuran $10 \mathrm{~mm} \times 2 \mathrm{~mm}$. Kemudian bubuk SIK ditimbang sebanyak 0,6 gram dan liquid SIK sebanyak 0,3 gram untuk membuat sampel. Pengadukan dilakukan dengan membagi bubuk menjadi 2 bagian, bagian pertama diaduk dengan liquid selama 20 detik dan dilanjutkan dengan bagian kedua selama 10 detik. Setelah sampel diaduk hingga homogen, kemudian sampel dimasukkan ke dalam mould menggunakan plastic filling. Permukaan sampel ditutup dengan mylar strip dan glass plate serta diberi pemberat $1 \mathrm{~kg}$. Sampel dibiarkan mengeras selama 5 menit, kemudian pemberat, glass plate dan mylar strip dilepas. Sampel dikeluarkan dari mould, lalu dilakukan pengukuran menggunakan jangka sorong.

Sampel yang sudah dibuat disimpan dalam inkubator bersuhu $37^{\circ} \mathrm{C}$ selama 24 jam sebelum dilakukan uji kekasaran permukaan awal. Setelah dilakukan uji kekasaran permukaan awal, maka dilanjutkan dengan perendaman sampel dalam $\mathrm{pH}$ saliva kritis selama 7 hari di dalam inkubator bersuhu $37^{\circ} \mathrm{C}$ dan dilakukan uji kekasaran permukaan akhir. Saliva yang digunakan adalah saliva buatan dengan komposisi NaCL, KSCN, $\mathrm{NaHCO}_{3}, \mathrm{KCL}, \mathrm{Na}_{2} \mathrm{HPO}_{4}, \mathrm{KH}_{2} \mathrm{PO}_{4}$ dan memiliki $\mathrm{pH}$ 5,5 untuk mensimulasikan keadaan $\mathrm{pH}$ saliva kritis di dalam rongga mulut. Pengujian kekasaran permukaan dilakukan dengan menggunakan surface roughness tester merk sutrotonic s-100 series.

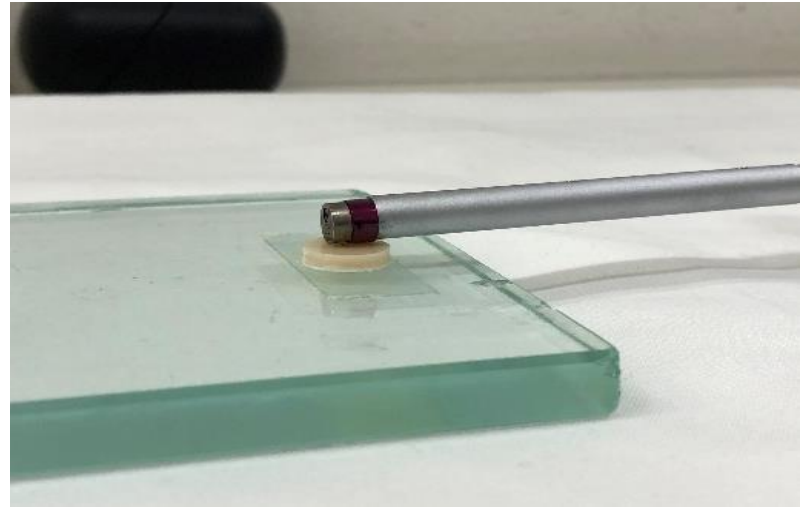

Gambar 1. Detektor surface roughness tester sutrotonic $s-100$ series diletakkan pada sampel

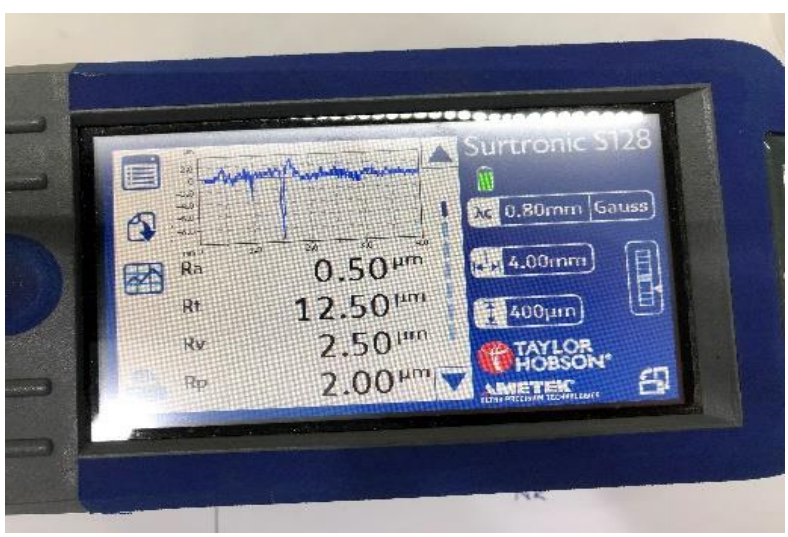

Gambar 2. Hasil uji kekasaran permukaan menggunakan surface roughness tester sutrotonic s100 series.

\section{HASIL PENELITIAN}

Data hasil penelitian yang diperoleh menunjukkan nilai rata-rata kekasaran permukaan akhir dari sampel SIK konvensional dan SIK nanokitosan mengalami peningkatan setelah perendaman pada $\mathrm{pH}$ saliva kritis $(5,5)$ selama 7 hari. Nilai peningkatan kekasaran permukaan diperoleh dari selisih nilai kekasaran sesudah perendaman dikurangi nilai kekasaran sebelum perendaman. Nilai peningkatan kekasaran pada kelompok SIK konvensional sebesar 0,133 $\pm 0,038$ $\mu \mathrm{m}$ dan SIK nanokitosan sebesar 0,122 $\pm 0,053 \mu \mathrm{m}$ 


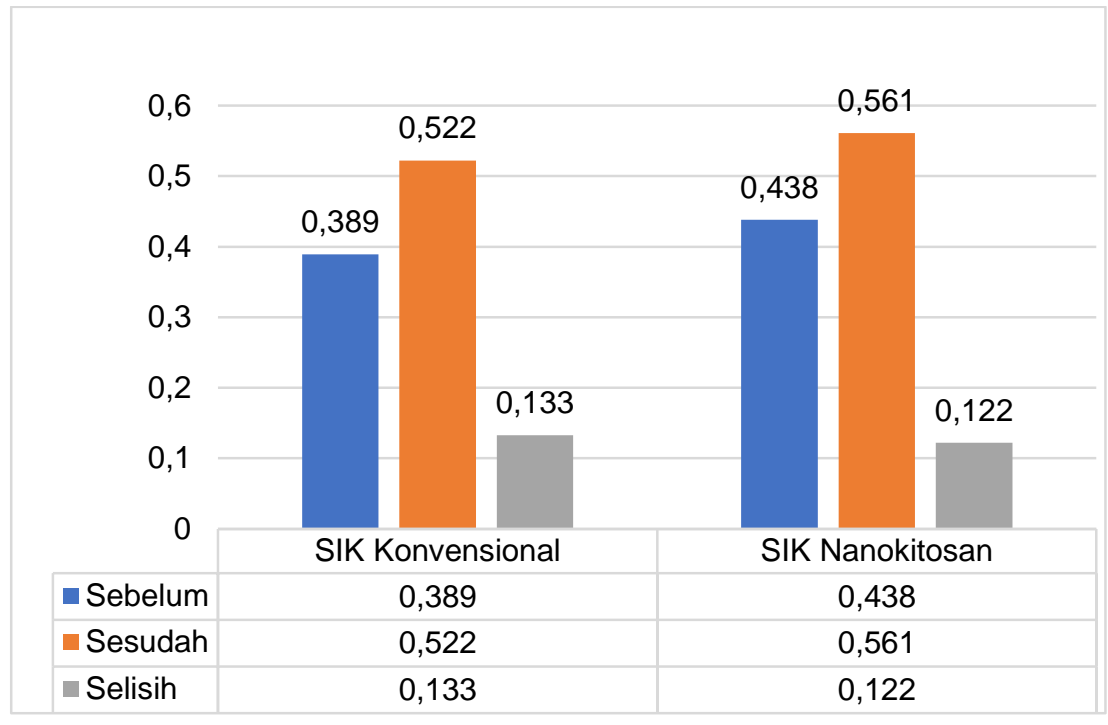

Gambar 3. Grafik hasil uji kekasaran permukaan

Tabel 1. Uji paired t-test kekasaran permukaan SIK konvensional dan SIK nanokitosan sebelum dan sesudah perendaman selama 7 hari dalam $\mathrm{pH}$ saliva kritis $(\mathrm{p}<0,05)$

\begin{tabular}{|c|c|c|c|c|c|}
\hline \multirow{2}{*}{ Perlakuan } & \multirow{2}{*}{$\mathbf{N}$} & \multicolumn{3}{|c|}{ Rata-rata kekasaran permukaan $\pm S D(\mu \mathrm{m})$} & \multirow{2}{*}{$\boldsymbol{P}$} \\
\hline & & Sebelum & Sesudah & Selisih & \\
\hline SIK Konvensional & 6 & $0,389 \pm 0,100$ & $0,522 \pm 0,086$ & $0,133 \pm 0,038$ & 0,001 \\
\hline SIK Nanokitosan & 6 & $0,438 \pm 0,104$ & $0,561 \pm 0,071$ & $0,122 \pm 0,053$ & 0,004 \\
\hline
\end{tabular}

Tabel 2. Uji independent t-test kekasaran permukaan SIK konvensional dan SIK modifikasi nanokitosan setelah perendaman selama 7 hari $(p>0,05)$

\begin{tabular}{cccc}
\hline Perlakuan & N & $\begin{array}{c}\text { Selisih rata-rata kekasaran } \\
\text { permukaan } \pm S \boldsymbol{D}(\boldsymbol{\mu m})\end{array}$ & $\boldsymbol{P}$ \\
\hline SIK Konvensional & 6 & $0,133 \pm 0,038$ & 0,713 \\
SIK Nanokitosan & 6 & $0,122 \pm 0,053$ & \\
\hline
\end{tabular}

Berdasarkan hasil uji paired t-test (tabel 1) dengan tingkat kemaknaan $\mathrm{p}<0,05$ yang artinya terdapat perbedaan bermakna, ditemukan pada kelompok SIK konvensional nilai $p=0,001 \quad(p<0,05)$ dan SIK nanokitosan didapatkan nilai $p=0,004$ $(p<0,05)$, artinya terdapat perbedaan yang bermakna pada SIK konvensional maupun SIK nanokitosan (Xylotrupes gideon) sebelum dan sesudah perendaman dalam $\mathrm{pH}$ saliva kritis selama
7 hari.

Berdasarkan hasil uji independent t-test (tabel 2) dengan tingkat kemankaan $\mathrm{p}<0,05$ yang artinya terdapat perbedaan bermakna, didapatkan nilai $p$ sebesar 0,713 ( $p>0,05)$ artinya tidak terdapat perbedaan bermakna antara SIK konvensional dan SIK nanokitosan yang telah dilakukan perendaman pada $\mathrm{pH}$ saliva kritis. Sehingga dapat disimpulkan bahwa penambahan nanokitosan terhadap SIK 
tidak memberikan perbedaan bermakna terhadap kekasaran permukaan pada perendaman $\mathrm{pH}$ saliva kritis selama 7 hari.

\section{DISKUSI}

Keadaan asam dalam rongga mulut yang berubah-ubah dapat menyebabkan potensi erosif terhadap kekasaran permukaan gigi ataupun bahan restorasi. ${ }^{12}$ Faktor yang mempengaruhi perubahan $\mathrm{pH}$ saliva salah satunya adalah diet karbohidrat. Diet karbohidrat dapat mempercepat demineralisasi email gigi, atau menghasilkan asam melalui proses glikolisis yang dapat menurunkan pH saliva menjadi kritis. ${ }^{8}$ Saliva membutuhkan waktu sekitar 30 menit hingga 2 jam untuk kembali ke $\mathrm{pH}$ normal tergantung dari faktor diet yang dikonsumsi. ${ }^{13}$ Kekasaran permukaan yang diakibatkan $\mathrm{pH}$ saliva asam dapat berdampak pada perubahan warna, retensi plak dan mikroorganisme hingga penyakit gingiva dalam rongga mulut. 8,12

Pada penelitian ini, nilai kekasaran permukaan sebelum perendaman SIK konvensional adalah $0,389 \pm 0,100 \mu \mathrm{m}$ dan SIK nanokitosan adalah $0,438 \pm 0,104 \mu \mathrm{m}$. Setelah perendaman terjadi peningkatan kekasaran permukaan pada kedua kelompok perlakuan. Nilai kekasaran permukaan pada SIK setelah perendaman dalam $\mathrm{pH}$ saliva kritis ditemukan lebih tinggi. Hal ini juga terlihat pada uji paired $t$-test pada kedua kelompok yang menunjukkan terdapat perbedaan bermakna $(p<0,05)$ pada kelompok SIK konvensional dan SIK nanokitosan setelah perendaman dalam $\mathrm{pH}$ saliva kritis. Hal ini menujukan bahwa $\mathrm{pH}$ saliva kritis dapat menyebabkan peningkatan kekasaran permukaan pada kedua kelompok. Hasil yang diperoleh ini sesuai dengan penelitian Viona (2016) yang menyatakan bahan restorasi yang terpapar asam dapat membentuk porus dan menyebabkan kekasaran permukaan. Nilai kekasaran permukaan awal SIK adalah $0,5363 \mu \mathrm{m}$ dan nilai akhir 0,6368 $\mu \mathrm{m}$ setelah perendaman dalam $\mathrm{pH}$ 2,9. ${ }^{3}$ Penelitian Salma (2019) juga menyatakan bahwa kekasaran permukaan tertinggi didapatkan ketika bahan restorasi berada dalam $\mathrm{pH}$ saliva kritis. ${ }^{10}$ Nilai kekasaran permukaan SIK juga akan meningkat apabila terpapar dengan larutan asam seperti pada minuman isotonik $(\mathrm{pH} 2,9)$ karena larutan asam menyebabkan terlarutnya ion-ion dari SIK yang akan membentuk porus sehingga terjadi peningkatan kekasaran permukaan. ${ }^{3}$

Media penyimpanan sampel SIK juga dapat mempengaruhi kekasaran permukaan. Penelitian terbaru menyatakan bahwa, SIK konvensional yang direndam pada air suling dengan suhu $37^{\circ} \mathrm{C}$ selama 24 jam mengalami peningkatan kekasaran permukaan, hal ini berbanding terbalik dengan SIK modifikasi resin yang tidak mengalami peningkatan kekasaran permukaan saat perendaman pada air suling maupun saliva buatan. ${ }^{11}$ Faktor lain yang menyebabkan peningkatan kekasaran permukaan adalah faktor mekanis dan kimiawi yang didapatkan dari $\mathrm{pH}$ saliva dan minuman berkarbonasi. Hasil uji statistik menunjukkan bahwa perendaman minuman berkarbonasi dengan $\mathrm{pH} 2,5$ dalam waktu tertentu dapat mempengaruhi kekasaran permukaan dari SIK. Kekasaran permukaan yang meningkat diakibatkan oleh $\mathrm{pH}$ rendah yang menyebabkan erosi pada permukaan SIK dan sifat korosif pada minuman berkarbonasi menyebabkan kelarutan pada ion SIK. ${ }^{14}$

SIK telah banyak mengalami modifikasi untuk memperbaiki sifat mekanis, fisik maupun kimiawi seperti penambahan resin, zirkonia, stronsium oksida, silika, nanokristal, zirkonomer karbomer hingga kitosan. Hasil modifikasi pada bahan SIK dapat memperbaiki sifat SIK sehingga dapat digunakan sebagai restorasi gigi posterior, anterior pada gigi tetap maupun pada gigi sulung. ${ }^{15}$ Pada penelitian terdahulu menunjukkan bahwa SIK 
konvensional memiliki kekasaran permukaan yang lebih tinggi dibandingkan Semen lonomer Kaca Modifikasi Resin (SIKMR), modifikasi perak maupun modifikasi larutan. Selain itu, modifikasi SIK nanokitosan 10\% dapat meningkatkan kekuatan tekan, kekuatan lentur, ketahanan aus dan pelepasan fluor yang lebih tinggi jika dibandingkan dengan SIK konvensional.

Pada pemeriksaan SEM (Scanning Electron Microscope) diperoleh bahwa permukaan SIK konvensional memilki rongga dan retakan, terlepas dari perbedaan nilai kekasaran permukaan, pola permukaan seperti ini juga ditemukan pada pemeriksaan SEM untuk bahan lainnya. Faktor yang menyebabkan terjadinya retakan adalah saat pemrosesan sampel untuk pengujian SEM, sedangkan rongga dapat tercipta ketika proses pencampuran bubuk dan cairan dari SIK. ${ }^{11}$

Pada penelitian ini dilakukan penambahan nanokitosan kumbang tanduk (Xylotrupes gideon) kedalam larutan SIK, dan didapatkan bahwa nilai peningkatan kekasaran permukaan SIK nanokitosan $(0,122 \pm 0,053 \mu \mathrm{m}) \quad$ lebih rendah dibandingkan SIK konvensional $(0,133 \pm 0,038 \mu \mathrm{m})$. Kitosan dalam bentuk nano mempunyai ukuran 10$1000 \mathrm{~nm}$ sehingga menunjukkan hasil modifikasi yang lebih efektif dengan stabilitas yang lebih baik, dan juga sitotoksisitas yang rendah. Penelitian Sundari (2016), juga menyatakan bahwa penambahan larutan kitosan $10 \% \mathrm{v} / \mathrm{v}$ dapat menurunkan kekasaran permukaan SIK jika dibandingkan dengan kekasaran permukaan SIK konvensional. Peningkatan ketahanan kitosan terhadap asam diduga karena gugus amina dan gugus hidroksil yang memiliki reaksi kimia tinggi. Gugus amina yang dimiliki kitosan bermuatan positif sehingga mampu menarik molekul yang bermuatan parsial negatif. Muatan positif ini menyebabkan gugus amina dan hidroksil pada kitosan berikatan dengan gugus hidroksil dan karboksilat pada SIK melalui ikatan hidrogen dan menurunkan tegangan permukaan. Penurunan tegangan permukaan akan meningkatkan gaya adhesi antar komponen sehingga SIK menjadi lebih tahan terhadap asam. ${ }^{9}$

\section{KESIMPULAN}

Hasil penelitian ini menunjukkan bahwa SIK nanokitosan kumbang tanduk (Xylotrupes Gideon) dapat menurunkan nilai kekasaran permukaan pada $\mathrm{pH}$ saliva kritis meskipun pada uji independent $t$-test tidak ada perbedaan bermakna $(p>0,05)$.

\section{DAFTAR PUSTAKA}

1. Pacifici E, Bossù M, Giovannetti A, La Torre G, Guerra F, Polimeni A. Surface roughness of glass ionomer cements indicated for uncooperative patients according to surface protection treatment. Ann Stomatol (Roma) [Internet]. 4(3-4):250-8. Available from: http://www.ncbi.nlm.nih.gov/pubmed/2461109 0\%0Ahttp://www.pubmedcentral.nih.gov/articl erender.fcgi?artid=PMC3935351

2. Guedes OA guirr., Borges ÁH, Bandeca MC oelh., Nakatani MK yose., de Araújo Estrela $\mathrm{CR}$ odrigue., de Alencar AH elen. $\mathrm{G}$, et al. Chemical and structural characterization of glass ionomer cements indicated for atraumatic restorative treatment. J Contemp Dent Pract. 2015;16(1):61-7.

3. Diansari V, Ningsih DS, Moulinda C. Evaluasi Kekasaran Permukaan Glass Ionomer Cement (GIC) Konvensional Setelah Perendaman Dalam Minuman Berkarbonasi. Cakradonya Dent J. 2016;8(2):111-6.

4. Pratiwi D, Annisa S. Pengaruh Sikat dan Pasta Gigi Anak Terhadap Kekasaran Permukaan Semen lonomer Kaca. J Mater Kedokt Gigi. 2019;8(1):7-11

5. Da Silva RC, Zuanon ACC. Surface roughness of glass ionomer cements indicated for atraumatic treatment (ART). Braz Dent J. 2006;17(2):106-9

6. Sundari I. Perbedaan Kekasaran Permukaan Gic Tanpa Dan Dengan Penambahan Kitosan Setelah Perendaman Minuman Isotonik. J Mater Kedokt Gigi. 2016;5:49-55.

7. Lely MA. Pengaruh $(\mathrm{pH})$ Saliva terhadap Terjadinya Karies Gigi pada Anak Usia 
Prasekolah. Bul Penelit Kesehat. 2017;45(4):241-8.

8. Gani BA, Soraya C, Sunnati S, Nasution Al, Zikri N, Rahadianur $\mathrm{R}$. The $\mathrm{pH}$ changes of artificial saliva after interaction with oral of artificial saliva after interaction with oral micropathogen. Dent J (Majalah Kedokt Gigi). 2012;45(4):234.

9. Komariah, Astuti L. Preparasi dan Karakteristik Kitin yang Terkandung Dalam Eksoskeleton Kumbanf Tanduk Rhinoceros Beetle (Xylotrupes Gideon L) dan Kutu Beras (Sitophilus oryzae L). Semin Nas IX Pendidik Biol. 2012;9:648-54.

10. Komariah, Callista F, Bustami A Del. Pretreatment Nano Kitosan Dan Nano Kalsium (X. gideon) Pada Aplikasi Home Bleaching Terhadap Kekerasan Email. Semin Nas Cendekiawan [Internet]. 2018;1(24608696):417-22. Available from: https://pdfs.semanticscholar.org/daca/6a4a09 12383b309a478c5ed024b4ec64b116.pdf

11. Bala O, Arisu HD, Yikilgan I, Arslan S, Gullu A. Evaluation of surface roughness ad hardness of different glass ionomer cements. Eur J Dent. 2012;6(1):79-86
12. Abdelghany $\mathrm{S}$, Hammouda $\mathrm{H}$, Abdellatif $\mathrm{AM}$. Effect of Saliva $\mathrm{pH}$ and Polishing Techniques on the Surface Roughness of Different Esthetic Restorative Materials in Primary Teeth. Pediatr Dent Diploma. 2019;78-85.

13. Ramadhani A. Uji Keedalaman Porositas Permukaan Bahan Pit dan Fissure Sealant Berbasis Resin Komposit dan Ionomer Kaca Setelah Direndam Saliva Buatan pH 5,5. Skripsi. 2017. 1-99 p.

14. Chair Effendi, M., Nugraeni, Y., Hartami, E., \& Nurul Ummah, A. Changes in the Surface Roughness of Glass Ionomer Cement and Zirconomer after Immersion in Carbonated Beverages. J Dent Indones. 2020;27(2): 85-90

15. Menezes-Silva, R., Cabral, R., Pascotto, R., Borges, A., Martins, C., Navarro, M., Sidhu, S., \& Leal, S. (2019). Mechanical and optical properties of conventional restorative glassionomer cements - a systematic review. Journal of Applied Oral Science, 27.

16. Komariah K, Ageng A, Kusuma I. Efek Kombinasi Asam Valproat dan Nano Kitosan Kumbang Tanduk (Xylotrupesgideon) Terhadap Viabilitas dan Sitotoksisitas Sel Kanker Lidah (HSC-3). Semin Nas Pakar ke 2 Tahun 2019. 2019;1:1-7. 